\title{
The primary care electronic health record: who's righting the software?
}

\section{INTRODUCTION}

In 2008 my practice had to change from Synergy to Vision to comply with accreditation requirements. After training we found Vision disappointing and, in some ways, worse than Synergy. I wondered if anything was being done to keep an official eye on electronic health care records so I thought l'd look into it.

\section{BACKGROUND}

Computers have largely replaced paper records in general practice in Scotland. ${ }^{1}$ This is, in many ways, a good thing but has the potential for unanticipated consequences. ${ }^{2}$ Accreditation is required for functionality in relation to administration, reporting, security, electronic data interchange, coding and certain aspects of prescribing, but not for other areas of clinical use. ${ }^{3}$ National guidelines by a range of authoritative UK bodies have set standards for clinical records ${ }^{4}$ and, in particular, for electronic health records (EHRs). ${ }^{3,5-9}$

\section{METHOD}

During 2009 I noted problems encountered both by my colleagues and myself in using components of our bundle of software. I excluded problems that were due to temporary technical faults or to lack of training and included those apparently related to software design. I studied the sequence of operations and windows involved in each problem. I then classified the problems and checked them against recommendations in national guidelines. I contacted guideline writers and systems suppliers, informed them of my findings and noted their responses. The forms of communication included: e-mail, face-to-face meetings, telephone conversations, and a poster and video at the annual conferences of The Royal College of General Practitioners (RCGP) and National Vision
User Group (NVUG) in 2009. I also created a website on which I published my work in progress. ${ }^{10}$ Before submitting this article for publication on 2 December 2010 I checked that the problems I describe below are still present in the software.

\section{RESULTS}

The EHR in our practice consists of: Contract+ (for QOF prompting), Docman (document management), ESCRO ([Enhanced Services Contracting Reporting Options], drug users), Microsoft Word (word processing), NHS24 encounter sheets (out-of-hours service), SCCRS ([Scottish Cervical Call-Recall System], smears), and Vision (core component of clinical system). There are national guidelines by the British Medical Association, Department of Health, NHS, RCGP, Scottish Clinical Information Management in Practice (SCIMP), and the Scottish Government. I've communicated with NHS Lothian, the Scottish Government, In Practice Systems, SCIMP, ESCRO, NVUG, Contract+ and SCCRS. Below are guideline recommendations with examples of the deficiencies of the various systems.

\section{Guidelines and deficiencies}

The EHR should be 'clear', 4,8 'accurate, '4,6,11 'complete' and timely', 6 and convey 'narrative'. ${ }^{6}$ Vision's Problem Pages list problems in alphabetical order without dates so there is no sense of chronology; other pages default to reverse chronology so that, especially for entries occupying more than one line, the narrative is lost. In Vision I'm unable to code fit frequency in the recommended Structured Data Area without a comment on aura, or to record 'currently teetotal' without selecting 'lifelong teetotal' or 'ex drinker'. Recording drug allergies in such a way as to trigger subsequent computerised warnings requires a precise Read Code although that's often unknown. In Vision, the field offered for date of last menstrual period becomes the date under which the note, with any free text, is listed in Journal View. In Vision, entering 'URTI' leads not to the most general ancestor code for URTI but to an end-node 'not otherwise specified' code which excludes all other types of URTI.

In the Read Code hierarchy (currently Quarter 3 2010) 'male homosexuality' (E2200) is a child of 'sexual deviations or disorders' (E22).

Entries made via Contract+ or ESCRO appear in Vision only after the patient's notes have been closed and re-opened. In SCCRS a date for last menstrual period has to be entered even when it's unknown and I'm unable to combine a normal cervix appearance with a referral or an abnormal appearance with no referral.

The EHR should avoid ambiguity, 'personal shorthand', 6 'meaningless phrases' and 'unnecessary abbreviations or jargon'. ${ }^{8}$ In Vision, 'Hepatitis_B Stage: B Given Special Risk Group' means that a hepatitis B booster was given, although it could be mis-read as indicating a second immunisation. The Vision screen displays field names and data in various combinations and permutations such as 'Height 1.62 metres O/E - height'.

EHR 'standards should facilitate not hinder the process of writing, communicating and retrieving clinical information, ${ }^{11}$ so that information is 'accessible' ${ }^{6}$ and care is safer and more efficient'. 11

In Vision an oral contraceptive note entry defaults to 'first service' even for subsequent entries; recording pulses leads to windows which add by default that other pulses or heart sounds are satisfactory; recording immunisation requires that the vaccine name be entered twice; and clinical information in the 'remarks' field of 
the Med3 window is invisible when the window is closed.

When drugs are reissued in Vision, 'notes for patient' and 'instalment dispensing' are visible on screen only when those respective windows are opened.

Our previous system, Synergy, had the facility of interval-specific prompts for, say, a hepatitis B booster 12 months after the third dose: Vision Guidelines have no facility for this. In Vision, changing dispensing arrangements for a patient needs to be done individually for each drug rather than once for all drugs.

Reading Docman documents requires a minimum of 1 click and 1 curse per page; and each Microsoft letter requires 3 clicks to enter, often at least 1 curse to read and 2 clicks to exit - if you forget to exit, you get an unresponsive screen with no explanation.

Entering a 'problem' in Vision requires two windows with multiple fields and can be completed without Read Coding so that disease registers are incomplete.

Prescribing systems 'should cross check prescriptions for any sensitivities or interactions where appropriate' and 'provide an audible/visual warning for the prescriber.' ${ }^{3}$ In Vision, depending on patient factors and user settings, warnings are so non-specific that the same number of clicks is needed to prescribe aqueous cream as to prescribe warfarin, drugs with quite different safety profiles.

Prescribing systems should 'provide a facility to record that the medication regime has been reviewed and confirmed'. ${ }^{3}$ In Vision, prescriptions are divided into repeat and acute drugs. Coding a review of a medication regime indicates that the list of repeat drugs is correct, but drugs might be added to or removed from this list subsequently without this being apparent to the next doctor. Acute drugs are not reviewed at all.

'Prescribing systems should display the appropriate generic name(s) with the trade name ... and list generic drugs first and branded products after' to reduce 'the possibility of mis-selection'. ${ }^{9}$ Vision defaults to a single alphabetical list of generic and proprietary drugs.
Prescriptions should be printed in '11 pitch'3 (11 characters per inch). Prescription dosages are printed in 15 pitch (15 characters per inch), which is smaller than 11 pitch; so, dosages are in smaller print than drug names and therefore harder to read.

\section{Responses by software and guideline writers}

Suppliers have made two relevant changes. In Contract+, the prompt to prescribe a beta-blocker for ischaemic heart disease in asthmatics used to be accompanied by a warning icon: it's now accompanied by a warning statement. In Vision, the only 'Journal' page available included a record of all prescriptions issued making it hard to discern the clinical notes: this is still the default journal but a second page called 'My Journal' has now been added - this excludes the record of prescriptions issued which makes the notes easier to read, but it also excludes other entries such as medication reviews along with any free text attached to them.

I've had many interesting discussions with unfailingly courteous computer experts. In fact, I found some to be so kind that I think they were concerned for my wellbeing. These experts tended to emphasise the need for more training. On further discussion, however, they proposed that, when systems were being set up, the trainers should customise the software to suit the individual practices and users before leaving the building.

\section{DISCUSSION}

The EHR in my practice fails to meet national guidelines and there's no system for monitoring or rectifying this. Failings are found in all components of the software bundle. The core of the record - rather than the add-ons - provides most of my examples because it's the part of the EHR most used. That the core component happens to be Vision doesn't mean that other software packages are any better: on the contrary, from what I gather, Vision is better than most. And, although I've tried to be objective, ultimately my comments reflect a personal view.

Computerising the EHR has several potential benefits: ${ }^{2}$ mechanisation; multiuser access; improved navigation and legibility; support for patient care; and secondary use of data. When I compare the EHR with the previous paper-based system some of the benefits are so selfevident that no research might be needed. For instance, instead of the error-prone labour of writing out repeat prescriptions by hand and recording details in the notes, we can now print and record these accurately with a few clicks of a mouse. Hospital letters reach the patients' notes and my desk within minutes of arriving in the building. However, there are risks of unintended consequences. For instance, the doctor may fail to see important information in the lower half of a Docman document because it needs cursing to be visible. Applications such as clinical decision support software and electronic prescribing systems haven't been shown to improve practitioner performance or patient outcomes, and are largely unregulated in the UK. ${ }^{2}$

Defects in software arise partly because clinicians aren't sufficiently involved in standard setting ${ }^{11}$ and in design. ${ }^{2,12}$ Clumsy software requires clinical practice to change to accommodate the computer ${ }^{11}$ and takes the clinician's attention away from the patient. ${ }^{13}$ 'Work-arounds' to 'get the job done' increase costs and worsen patient outcomes. ${ }^{14}$

Problems can't be rectified by individual general practices because choice of software is often made at a higher level in the health service..$^{15}$ They can't be rectified by the helpful user groups, trainers, and other company personnel who are all doing their best. And they can't be solved by a single agency when packages are made up of software from multiple agencies: ${ }^{14}$ Vision, for instance, uses Multilex and Read Code databases; and the ingenious people of Lothian who send laboratory results and out-of-hours encounter sheets to my desktop are manipulating preexisting components.

Systems need to be 'accredited against national standards' ${ }^{6}$ but there seems to be no organisation with the remit and mandate to do this.

\section{CONCLUSION}

I'm an enthusiast for the EHR. Mechanisation, centralisation, navigation and audit are wonderful. But the clever and 
hard-working people who create the EHR are motivated not just to provide GPs with useful tools but to change general practice for the better. And such crusades can do harm as well as good. ${ }^{16}$ The EHR should be R.A.W.E. - Read And Written Easily. ${ }^{10}$ And systems need to be designed and customised so they're ready for use when we GPs start our morning surgeries.

\section{Wilfrid Treasure}

\section{ACKNOWLEDGMENTS}

I'm grateful to Muirhouse Medical Group and to the representatives of the various organisations referred to for their help with this work.

\section{REFERENCES}

1. Scottish Government. Health in Scotland 2004. Chapter 5: eHEALTH.

http://www.scotland.gov.uk/Publications/2005/03/20877 154852 (accessed 14 Dec 2010).

2. Car J, Black A, Anandan C, et al. The Impact of eHealth on the Quality and Safety of Healthcare: a systemic overview and synthesis of the literature. Report for the NHS Connecting for Health Evaluation Programme. Edinburgh: The University of Edinburgh and Imperial College London, 2008.

3. The National Health Service Management Executive Primary Care Directorate. Requirements for accreditation for general practice computer systems in Scotland. 1999. http://www.show.scot.nhs.uk/publications/me/gpcompu terrecords/rfavl.pdf (accessed 14 Dec 2010).

4. General Medical Council. Good Medical Practice: providing good clinical care. 2010. http://www.gmcuk.org/guidance/good_medical_practice/good_clinical_ care_index.asp (accessed 14 Dec 2010).

5. The Scottish Government. Records Management best practice in relation to the creation, use, storage, management and disposal of NHS records. 2008 http://www.scotland.gov.uk/Publications/2008/07/01082 955/0 (accessed 14 Dec 2010).

6. General Practitioners Committee, Royal College of General Practitioners, Department of Health. Good practice guidelines for general practice electronic patient records (version 3.1). 2005.

http://www.dh.gov.uk/prod_consum_dh/groups/dh_dig italassets/@dh/@en/documents/digitalasset/dh_4116707 pdf (accessed 14 Dec 2010)

7. Scottish Clinical Information Management in Practice. Good Practice Guide.

http://www.scimp.scot.nhs.uk/gpg.html (accessed 14 Dec 2010).

8. Scott B, NHS Information Standards Board. NHS health record and communication practice standards for team based care. http://www.e-healthinsider.com/img/document_library0282/healthrec_com practice.pdf (accessed 14 Dec 2010).

9. National Patient Safety Agency. Design for Patient Safety: guidelines for safe on-screen display of medication information. 2010

http://www.nrls.npsa.nhs.uk/resources/?entryid45=6671 $3 \& \mathrm{q}=0 \% \mathrm{c} 2 \%$ acdesign + for + patient + safety $\% \mathrm{c} 2 \% \mathrm{ac}$ (accessed 14 Dec 2010).

10. Treasure W. R.A.W.E. COMPUTING http://rawecomputing.weebly.com/index.html (accessed 14 Dec 2010).

11. Academy of Medical Royal Colleges, NHS. A clinician's guide to record standards - part 1: why standardise the structure and content of medical records? http://www.rcoa.ac.uk/docs/Clinicians-Guide-Part-1Context.pdf (accessed 14 Dec 2010).
12. Greenhalgh T, Potts HWW, Wong G, et al. Tensions and paradoxes in electronic patient record research: a systematic literature review using the meta-narrative method. Milbank Q 2009; 87(4): 729-788.

13. Silverman J, Kinnersley P. Doctors' non-verbal behaviour in consultations: look at the patient before you look at the computer. Br J Gen Pract 2010; 60(571): 76-78.

14. Johnson CW. Why did that happen? exploring the proliferation of barely usable software in healthcare systems. Qual Saf Health Care 2006; 15(suppl 1): i76-i81.

15. Purves I. Where now with clinical computer systems? $\mathrm{Br}$ $J$ Gen Pract 2003; 53(496): 835-836.

16. Kay S, Purves I. The electronic medical record and the 'story stuff': a narrativistic model. In: Greenhalgh T, Hurwitz B, eds. Narrative based medicine: dialogue and discourse in clinical practice. London: BMJ Books; 1998 185-201.

DOI: 10.3399/bjgp11X556443

\section{Now that he is in the county jail}

Now that he is in the county jail, the madman who attempted to assassinate US Representative Gabrielle Giffords, murdering six other people in the process, will get the psychiatric services he needs. Prisons and jails have become the de facto mental health systems in the US. The schools he attended dealt with his frightening behaviour by telling him to stay away. No one - schools, neighbours, his family - took responsibility to stop him. While all countries have madmen, most countries don't make it legal for madmen to purchase handguns and carry them on the streets. That is a much higher order of legislative insanity which, sadly, is not limited to Arizona.

The genocide in Rwanda was in part driven by radio announcers urging people to kill their neighbours. Immersing a madman with a gun in the endless stream of anger and political invective from talk radio seems to be, while not as explicit as Rwanda, in many ways the same thing. The pitchmen of hate demur. 'Not my fault' they say and continue to vilify anyone who says otherwise. If the madman is found guilty in a trial, he could be killed, because Arizona still has the death penalty. That would satisfy nobody and doesn't address the problem of a legal system that makes murder easy. Other madmen, also able legally to buy guns and tote them around, are out there being prodded and taunted by demagogues. It just continues.

\section{John Frey}

DOI: 10.3399/bjgp11X556452 